\title{
Chronic Energy Deficiency and Its Determinant Factors among Adults Aged 18-59 Years in Ethiopia: A Cross-Sectional Study
}

\author{
Samuel Dagne $\mathbb{D D}^{1},{ }^{1}$ Yonatan Menber, ${ }^{1}$ Yosef Wassihun, ${ }^{1}$ Gedefaw Dires $\left(\mathbb{D},{ }^{2}\right.$ Atitegeb Abera, ${ }^{2}$ \\ Seteamlak Adane, ${ }^{2}$ Melese Linger $\mathbb{D}^{2},{ }^{2}$ and Zelalem T. Haile ${ }^{3}$ \\ ${ }^{1}$ School of Public Health, College of Medicine and Health Science, Bahir Dar University, Bahir Dar, Ethiopia \\ ${ }^{2}$ Department of Public Health, College of Health Science, Woldia University, Woldia, Ethiopia \\ ${ }^{3}$ Ohio University, Athens, USA \\ Correspondence should be addressed to Samuel Dagne; samdagseg@gmail.com
}

Received 4 September 2020; Revised 4 December 2020; Accepted 29 December 2020; Published 6 January 2021

Academic Editor: Roxana Valdés-Ramos

Copyright (C) 2021 Samuel Dagne et al. This is an open access article distributed under the Creative Commons Attribution License, which permits unrestricted use, distribution, and reproduction in any medium, provided the original work is properly cited.

Background. The prevalence of undernutrition in low- and middle-income countries is still remarkably high. Undernutrition during adulthood is a greater risk factor for low productivity, poor health, and mortality. There is limited information on the prevalence and determinants of chronic energy deficiency in Ethiopia. Objective. To assess the prevalence and determinants of chronic energy deficiency among adults aged 18-59 years in Ethiopia. Method. A secondary data analysis was conducted using the data obtained from the 2016 Ethiopia Demographic and Health Survey. Data were collected using a multistage stratified cluster sampling technique, and the analytic sample consisted of 9,280 adults aged 18-59 years. The chi-square test and multivariable logistic regression analyses were used, and $p$ value $<0.05$ was taken as statistically significant. Result. A total of 9280 adults aged 18-59 years were included in the study and 2911 (28.7\%) (95\% CI: 27.0\%-30.4\%) of whom were chronic energy deficient. Adults who have no work $(\mathrm{AOR}=1.41,95 \% \mathrm{CI}: 1.16,1.72)$, male adults from Tigray region (AOR =2.23, 95\% CI: 1.61, 3.09), Afar region $(\mathrm{AOR}=2.98,95 \% \mathrm{CI}: 2.04,4.36)$, Somali region $(\mathrm{AOR}=3.14,95 \% \mathrm{CI}: 2.19,4.52)$, Gambella region $(\mathrm{AOR}=1.89,95 \% \mathrm{CI}: 1.29$, 2.76), Harari region $(\mathrm{AOR}=1.54,95 \% \mathrm{CI}: 1.09,2.19)$, Amhara region ( $\mathrm{AOR}=1.53,95 \% \mathrm{CI}: 1.09,2.13)$, Oromia region $(\mathrm{AOR}=1.53,95 \% \mathrm{CI}: 1.07,2.19)$, Dire Dawa $(\mathrm{AOR}=1.45,95 \% \mathrm{CI}: 1.03,2.05)$, adults live lonely $(\mathrm{AOR}=1.44,95 \% \mathrm{CI}: 1.21,1.71)$, and adults residing in poor wealth index households ( $\mathrm{AOR}=1.26: 95 \% \mathrm{CI}: 1.07,1.49$ ) were significantly associated with chronic energy deficiency. Conclusion and recommendation. Chronic energy deficiency among male adults in Ethiopia was a high public health problem. Marital status, wealth index, occupation, and region were significant predictors of chronic energy deficiency. The Ministry of Health with other partners should strictly monitor and evaluate interventions that are being applied and should give focus to adult men to prevent malnutrition.

\section{Introduction}

Nowadays, low- and middle-income countries are currently attacked by a double burden of malnutrition. The rates of overweight and obesity are increasing much faster in the developing world. The prevalence of undernutrition is still remarkably high [1-4]. Chronic energy deficiency (CED) is defined as a steady-state at which a person is in energy balance, although at a "cost" either in terms of health risk or as an impairment of functions and health [5]. Chronic energy deficiency can also be defined based on body mass index (BMI) as $<18.5 \mathrm{~kg} / \mathrm{m}^{2}[6,7]$.
Chronic energy deficiency during adulthood is associated with different adverse functional consequences. It increases the risk of morbidity, and mortality together with decreased mental and cognitive development reduces educational achievement and labor productivity [8-11].

The most common contributing factors to chronic energy deficiency among adults include inadequate diet intake, socioeconomic status, and infection [12-14].

Today, nearly one in three persons globally suffers from at least one form of malnutrition: wasting, stunting, vitamin and mineral deficiency, overweight or obesity, and dietrelated noncommunicable diseases (NCDs). In 2003, about 
$7.2 \%$ of adults worldwide were underweight [3]. In 2014, about 462 million (18.5\%) adults worldwide were underweight. Of this, 40.6 million $(8.8 \%)$ were men. More than $20 \%$ of men in India, Bangladesh, Timor-Leste, Afghanistan, Eritrea, and Ethiopia were underweight [15].

According to the 2011 Ethiopia Demographic Health Survey (EDHS), the prevalence of male adult thinness or underweight was $28.9 \%$. Of these, $21.4 \%$ was mild underweight and $7.3 \%$ was moderate to severe underweight [16]. The prevalence of CED was highest in the Somali region (62.0\%) and lowest in Addis Ababa (22.0\%) [16]. In Ethiopia, the prevalence of male adult CED increased from $10.8 \%$ in 2003 to $25.3 \%$ in 2011 [3, 16].

The United Nations set the sustainable development goal (SDG) targets a reduction in a different form of malnutrition by 2030 [17-19]. The World Health Organization (WHO) also sets a policy brief called double-duty actions for nutrition to end all burdens of malnutrition by 2030 [20].

The Ethiopian government identified different forms of undernutrition in the selected group such as children, adolescents, pregnant, and lactating women as the key priority indicators for national development. Besides global initiatives, the Ethiopian government had exerted many efforts, and bold actions were taken in health and other nutritionsensitive and specific interventions. The Seqota declaration reflects the commitment to ending undernutrition by 2030 using the multisectoral National Nutrition Program (NNPII) as a guiding framework to achieve this goal [19, 21-24].

Although there is limited documented data on male adult CED in Ethiopia, available sources documented increments in the prevalence of CED from $10.8 \%$ to $28.9 \%$ between 2003 and 2011 [3, 16]. However, almost all nutrition-related policies, strategies, and programs in Ethiopia give priority to undernutrition among special target groups such as children, adolescents, pregnant, and lactating. To some extent, little attention is also now given to the current emerging adult obesity. But, chronic energy deficiency among male adults is a forgotten agenda in Ethiopia. Moreover, lifecycle malnutrition can be tackled by intervening at all stages of life and all forms of malnutrition.

At the same time in Ethiopia, though there is too huge available data on published literature on undernutrition and concurrent morbidity, studies on CED among male adults are too limited. Finding from this study also helps to draw conclusions and to translate findings into policies and practices. Therefore, this study aimed to investigate the prevalence and determinant factors of CED among adults aged 18-59 years old in Ethiopia.

1.1. Study Design and Setting. Secondary data analysis was conducted using the data obtained from 2016 EDHS. EDHS was a cross-sectional community-based study that was conducted from January to June 2016. A detailed description of study design and methods for the 2016 EDHS is available elsewhere [25]. In brief, a two-stage stratified cluster sampling technique was used using the 2007 Ethiopia Population and Housing Census as the sampling frame. In the first stage, 645 enumeration areas (EA) were selected using probability proportional to the EA size. In the second stage, 28 households per EA were selected with an equal probability of systematic selection. Eligible participants included all adult men aged between 18 and 59 years. Additionally, in all selected households, weight and height measurements were collected from male adults aged 18-59 years $(n=11,100)$. After excluding adult male participants who did not have a response to the outcome variable, we restricted our analytical sample to 9,280 males aged 18-59 years.

\section{Measurement}

2.1. Dependent Variable. The nutritional status of adult men was screened by measuring height and weight and calculating BMI. The height of adult men aged 18-59 years was measured using a height scale. The men standing upright with their barefoot and the men's heads, shoulders, buttocks, knees, and heels were made to touch the height scale. The reading was recorded to the nearest $0.1 \mathrm{~cm}$. The weight of study participants was measured with minimum/light/ clothing and no shoes with the reading recorded to the nearest $0.1 \mathrm{~kg}$ [26]. BMI was calculated by dividing weight in kilograms by height in meters squared $\left(\mathrm{kg} / \mathrm{m}^{2}\right)$. Adult men with a BMI of less than $18.5 \mathrm{~kg} / \mathrm{m}^{2}$ were considered as exhibiting chronic energy deficiency $[5,27]$. The body mass index (BMI) values of less than 16, 16-16.99, and 17-18.4 were used to classified adults as severe, moderate, and mild CED, respectively. BMI of 18.5-24.9 was classified as normal weight [6].

2.2. Independent Variables. Based on existing literature, the following covariates were selected: anemia, age, household head sex, number of children in the household, family size, education level, occupational status, marital status, and place of residence, religion, household wealth index, region, alcohol intake, and chat chewing. Anemia in adults was defined based on the WHO recommendation, and hemoglobin level $<13 \mathrm{~g} / \mathrm{dl}$ was categorized as anemic [6]. The household wealth index was computed using principal components analysis on the household asset and was categorized into five wealth quintiles (lowest, second, middle, fourth, and highest) [28]. In this study, lowest and second wealth quintiles were grouped to poor, while the fourth and highest wealth quintiles were grouped to rich. A detailed description of the calculation of the household wealth index is available elsewhere [25].

2.3. Data Management and Statistical Analysis. Data were extracted from EDHS 2016, and further coding and analysis were performed using SPSS version 20. Throughout the analysis, sample weights were carried out to adjust for nonproportional allocation of the sample to strata and regions during the survey process and to restore the representativeness. Descriptive statistics were conducted to provide a summary of the characteristics of the study sample. Bivariate analysis with chi-square statistics was performed to test the independence of distribution between the independent variables and chronic energy deficiency. A multiple 
logistic regression model was then fitted to identify the determinants of chronic energy deficiency. To control the confounding effect, all variables with a $p$ value less than 0.25 in the bivariate analysis were included in the final regression model. In the final model, variables with a $p$ value less than 0.05 were considered as significantly associated with CED. The corresponding odds ratio with $95 \%$ confidence intervals was reported. Sampling weights that accounted for complex survey design were incorporated in all analyses. All statistical analyses were conducted using SPSS version 20.0.

\section{Results}

Table 1 presents the characteristics of the study population. Most of the households, 5664 (64.9\%), had five and more family sizes. About 3709 (44.0\%) adults had a primary education level. The majority of study participants, 6874 (83.8\%), were rural residents. About 3661 (35.95\%) adults reside in poor wealth index households. About 4304 (48.3\%) study subjects had a history of alcohol intake (Table 1).

The nutritional status of subjects is shown in Figure 1. The mean height, weight, and body mass index (BMI) of the subjects were $168.5 \mathrm{~cm}, 55.7 \mathrm{~kg}$, and $19.6 \mathrm{~kg} / \mathrm{m}^{2}$, respectively. The overall frequencies of CED (BMI $<18.5 \mathrm{~kg} / \mathrm{m}^{2}$ ) was $28.7 \%$ (95\% CI: $27.0 \%-30.4 \%$ ). About $1.8 \%$ and $5.8 \%$ of subjects had severe and moderate CED, respectively. Based on the WHO (1995) classification, the prevalence of CED among this population was high (20-39\%), and thus, the situation is a serious public health problem.

Differences in the proportions of chronic energy deficiency by participant characteristics are presented in Table 2. The prevalence of CED was higher among households with $\geq 5$ family size than households with $<5$ family members $(p<0.001)$. The proportion of CED was higher among households with a poor wealth index than households with a high wealth index. Factors that were associated with CED included anemia, sex of head of household, educational status, place of residence, religion, wealth status, marital status, occupational status, adults age, family size, alcohol consumption, and region (Table 2).

Chronic energy deficiency and anemia comorbidity are shown in Figure 2. A higher proportion of chronic energy deficiency was observed in anemic (33.0\%) male adults than nonanemic (28.3\%) adults.

Table 3 presents the multivariable-adjusted association between factors and CED.

In the bivariate regression analysis, anemia, educational status, place of residence, religion, wealth status, marital status, occupational status, adults age, alcohol consumption, and region had a $p$ value $<0.05$. In the multivariable analysis, only occupation, marital status, household wealth index, and region were independent predictors of CED at a $p$ value $<0.05$.

Compared to adults who have work, the odds of CED were higher in adults who have no work (95\% CI: 1.23, 1.82). Compared to adults who have married, the odds of CED
TABle 1: Descriptive statistics of the study sample $(N=9280)$.

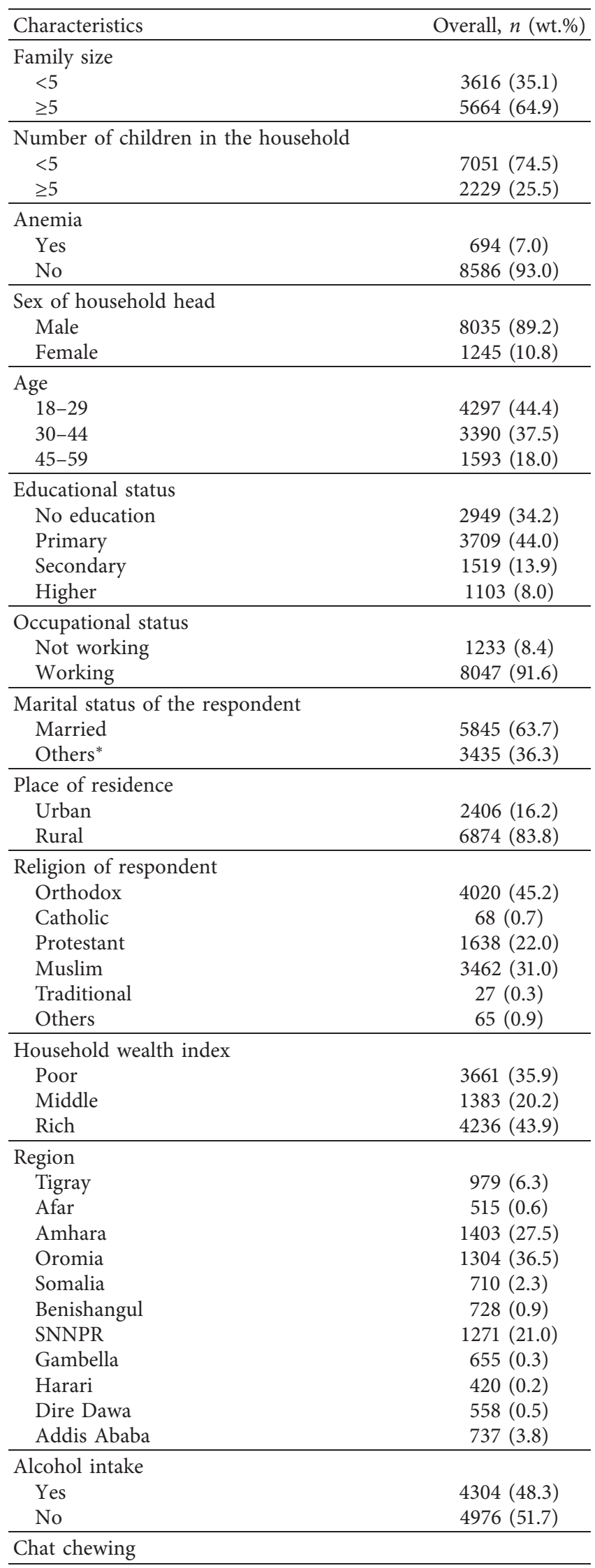


TABLE 1: Continued.

\begin{tabular}{lc}
\hline Characteristics & Overall, $n$ (wt.\%) \\
\hline Yes & $3002(28.6)$ \\
No & $6278(71.4)$ \\
\hline Chronic energy deficiency & \\
Yes & $2911(28.7)$ \\
No & $6369(71.3)$ \\
\hline
\end{tabular}

*Separated, widowed, divorced, living with a partner, and single. SNNPR, Southern Nations, Nationalities, and Peoples' Region. Weighted percentages were obtained to control for complex sample design.

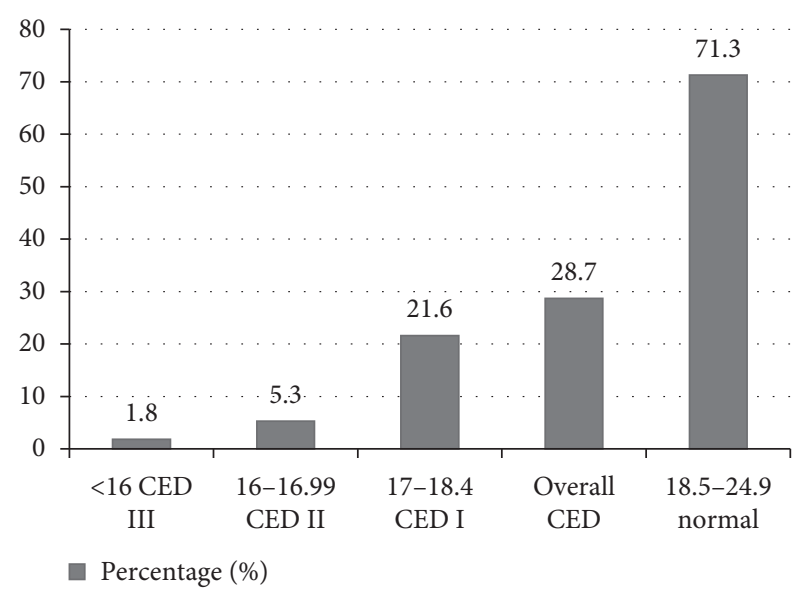

FIGURE 1: Nutritional status of adults aged 18-59 years in Ethiopia: EDHS $2016(N=9280)$.

TABLE 2: Characteristics of the study sample by chronic energy deficiency $(N=9280)$.

\begin{tabular}{|c|c|c|c|}
\hline \multirow{2}{*}{ Characteristics } & \multicolumn{2}{|c|}{ Chronic energy deficiency } & \multirow{2}{*}{$p$} \\
\hline & Yes, $n$ (wt.\%) & No, $n$ (wt.\%) & \\
\hline \multicolumn{4}{|l|}{ Family size } \\
\hline$<5$ & $1040(27.4)$ & $2576(72.6)$ & \multirow{2}{*}{$<0.001$} \\
\hline$\geq 5$ & $1871(29.3)$ & $3793(70.7)$ & \\
\hline \multicolumn{4}{|c|}{ Number of children in the household } \\
\hline$<5$ & $2227(29.4)$ & $4824(70.6)$ & \multirow{2}{*}{0.425} \\
\hline$\geq 5$ & $684(26.5)$ & $1545(73.5)$ & \\
\hline \multicolumn{4}{|l|}{ Anemia } \\
\hline Yes & $272(33.0)$ & $422(67.0)$ & \multirow{2}{*}{$<0.001$} \\
\hline No & $2639(28.3)$ & $5947(71.7)$ & \\
\hline \multicolumn{4}{|c|}{ Sex of household head } \\
\hline Male & $2477(28.4)$ & $5558(71.6)$ & \multirow{2}{*}{0.004} \\
\hline Female & $434(30.9)$ & $811(69.1)$ & \\
\hline \multicolumn{4}{|l|}{ Age } \\
\hline $18-29$ & $1514(32.7)$ & $2783(67.3)$ & \multirow{3}{*}{$<0.001$} \\
\hline $30-44$ & $925(24.5)$ & $2465(75.5)$ & \\
\hline $45-59$ & $472(27.3)$ & $1121(72.7)$ & \\
\hline \multicolumn{4}{|l|}{ Educational status } \\
\hline No education & $1019(29.4)$ & $1930(70.6)$ & \multirow{4}{*}{$<0.001$} \\
\hline Primary & $1153(29.3)$ & $2556(70.7)$ & \\
\hline Secondary & $469(28.5)$ & $1050(71.5)$ & \\
\hline Higher & $270(22.3)$ & $833(77.7)$ & \\
\hline \multicolumn{4}{|c|}{ Occupational status } \\
\hline Not working & $549(40.3)$ & $684(59.7)$ & \multirow{2}{*}{$<0.001$} \\
\hline Working & $2362(27.6)$ & $5685(72.4)$ & \\
\hline
\end{tabular}

TABle 2: Continued.

\begin{tabular}{|c|c|c|c|}
\hline \multirow{2}{*}{ Characteristics } & \multicolumn{2}{|c|}{ Chronic energy deficiency } & \multirow{2}{*}{$p$} \\
\hline & Yes, $n$ (wt.\%) & No, $n$ (wt.\%) & \\
\hline \multicolumn{4}{|c|}{ Marital status of the respondent } \\
\hline Married & $1679(25.6)$ & $4166(74.4)$ & \multirow{2}{*}{$<0.001$} \\
\hline Others & $1232(34.1)$ & $2203(65.9)$ & \\
\hline \multicolumn{4}{|c|}{ Place of residence } \\
\hline Urban & $578(22.8)$ & $1828(77.2)$ & \multirow{2}{*}{$<0.001$} \\
\hline Rural & $2333(29.8)$ & $4541(70.2)$ & \\
\hline \multicolumn{4}{|c|}{ Religion of respondent } \\
\hline Orthodox & $1095(27.2)$ & $2925(72.8)$ & \multirow{6}{*}{$<0.001$} \\
\hline Catholic & $33(51.4)$ & $35(48.6)$ & \\
\hline Protestant & $479(27.2)$ & $1159(72.8)$ & \\
\hline Muslim & $1278(31.6)$ & $2184(68.4)$ & \\
\hline Traditional & $7(23.6)$ & $20(76.4)$ & \\
\hline Others & $19(21.2)$ & $46(78.8)$ & \\
\hline \multicolumn{4}{|c|}{ Household wealth index } \\
\hline Poor & $1430(33.0)$ & $2231(67.0)$ & \multirow{3}{*}{$<0.001$} \\
\hline Middle & $413(27.6)$ & $970(72.4)$ & \\
\hline Rich & $1068(25.6)$ & $3168(74.4)$ & \\
\hline \multicolumn{4}{|l|}{ Region } \\
\hline Tigray & $376(37.8)$ & $603(62.2)$ & \multirow{11}{*}{$<0.001$} \\
\hline Afar & $263(46.7)$ & $252(53.3)$ & \\
\hline Amhara & $388(27.8)$ & $1015(72.2)$ & \\
\hline Oromia & $394(29.4)$ & $910(70.6)$ & \\
\hline Somalia & $345(48.8)$ & $365(51.6)$ & \\
\hline Benishangul & $201(29.0)$ & $527(71.0)$ & \\
\hline SNNPR & $311(25.0)$ & $960(75.0)$ & \\
\hline Gambella & $236(31.6)$ & $419(68.4)$ & \\
\hline Harari & $114(27.5)$ & $306(72.5)$ & \\
\hline Dire Dawa & $154(27.1)$ & 404 (72.9) & \\
\hline Addis Ababa & $129(17.4)$ & $608(82.6)$ & \\
\hline \multicolumn{4}{|l|}{ Alcohol intake } \\
\hline Yes & $1162(26.5)$ & $3142(73.5)$ & \multirow{2}{*}{$<0.001$} \\
\hline No & $1749(30.7)$ & $3227(69.3)$ & \\
\hline \multicolumn{4}{|l|}{ Chat chewing } \\
\hline Yes & $961(30.0)$ & $2041(70.0)$ & \multirow{2}{*}{0.355} \\
\hline No & $1950(28.1)$ & $4328(71.9)$ & \\
\hline
\end{tabular}

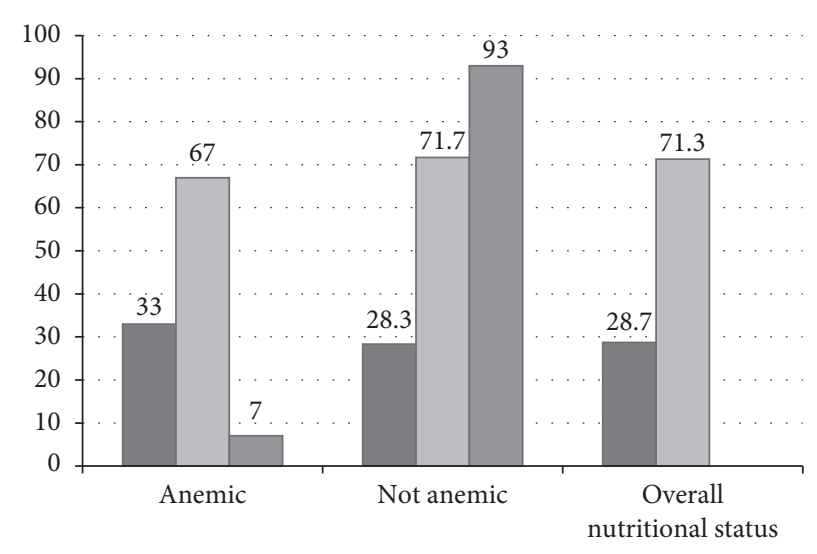

$$
\begin{aligned}
& \text { BMI }<18.5 \mathrm{~kg} / \mathrm{m}^{2} \\
& \text { BMI } 18.5-24.9 \mathrm{~kg} / \mathrm{m}^{2} \\
& \text { Overall anemia }
\end{aligned}
$$

FIgURE 2: Chronic energy deficiency anemia comorbidity among adults aged $18-59$ years old in Ethiopia: EDHS $2016(n=9280)$. 
TABLE 3: Factors associated with chronic energy deficiency among adults aged 18-59 years in Ethiopia: EDHS 2016 ( $N=9280)$.

\begin{tabular}{|c|c|c|c|c|}
\hline & Unadjusted OR (95\% CI) & $p$ & ${ }^{*}$ Adjusted OR (95\% CI) & $p$ \\
\hline $\begin{array}{l}\text { Family size } \\
\quad<5 \\
\geq 5 \\
\end{array}$ & $\begin{array}{c}0.91(0.79,1.04) \\
\text { Reference }\end{array}$ & 0.181 & $\begin{array}{c}0.95(0.82,1.10) \\
\text { Reference }\end{array}$ & 0.524 \\
\hline $\begin{array}{c}\text { Anemia } \\
\text { Yes } \\
\text { No } \\
\end{array}$ & $\begin{array}{c}1.23(1.05,1.55) \\
\text { Reference }\end{array}$ & 0.045 & $\begin{array}{c}1.17(0.93,1.48) \\
\text { Reference }\end{array}$ & 0.163 \\
\hline $\begin{array}{l}\text { Sex of household head } \\
\text { Male } \\
\text { Female } \\
\end{array}$ & $\begin{array}{c}0.88(0.72,1.09) \\
\text { Reference }\end{array}$ & 0.254 & $\begin{array}{c}1.09(0.87,1.36) \\
\text { Reference }\end{array}$ & 0.437 \\
\hline $\begin{array}{l}\text { Age } \\
\qquad 18-29 \\
30-44 \\
45-59 \\
\end{array}$ & $\begin{array}{c}1.29(1.08,1.54) \\
0.86(0.71,1.05) \\
\text { Reference }\end{array}$ & $\begin{array}{l}0.006 \\
0.142\end{array}$ & $\begin{array}{c}1.09(0.87,1.37) \\
0.87(0.71,1.06) \\
\text { Reference }\end{array}$ & $\begin{array}{l}0.438 \\
0.164\end{array}$ \\
\hline $\begin{array}{l}\text { Education status } \\
\text { No education } \\
\text { Primary } \\
\text { Secondary } \\
\text { Higher } \\
\end{array}$ & $\begin{array}{c}1.44(1.12,1.86) \\
1.44(1.12,1.87) \\
1.39(1.04,1.84) \\
\text { Reference }\end{array}$ & $\begin{array}{l}0.004 \\
0.006 \\
0.024\end{array}$ & $\begin{array}{c}1.25(0.91,1.71) \\
1.21(0.90,1.61) \\
1.11(0.82,1.48) \\
\quad \text { Reference }\end{array}$ & $\begin{array}{l}0.169 \\
0.207 \\
0.515\end{array}$ \\
\hline $\begin{array}{l}\text { Occupation status } \\
\text { Not working } \\
\text { Working } \\
\end{array}$ & $\begin{array}{c}1.77(1.48,2.11) \\
\text { Reference }\end{array}$ & $<0.001$ & $\begin{array}{c}1.49(1.23,1.82) \\
\text { Reference }\end{array}$ & 0.001 \\
\hline $\begin{array}{l}\text { Marital status } \\
\text { Married } \\
\text { Others }^{\mathrm{a}} \\
\end{array}$ & $\begin{array}{c}\text { Reference } \\
1.51(1.33,1.71)\end{array}$ & $<0.001$ & $\begin{array}{c}\text { Reference } \\
1.44(1.21,1.71)\end{array}$ & $<0.001$ \\
\hline $\begin{array}{l}\text { Place of residence } \\
\text { Urban } \\
\text { Rural } \\
\end{array}$ & $\begin{array}{c}0.69(0.56,0.86) \\
\text { Reference }\end{array}$ & 0.001 & $\begin{array}{c}0.79(0.58,1.06) \\
\text { Reference }\end{array}$ & 0.122 \\
\hline $\begin{array}{l}\text { Household wealth index } \\
\text { Poor } \\
\text { Middle } \\
\text { Rich }\end{array}$ & $\begin{array}{c}1.43(1.24,1.65) \\
1.11(0.91,1.36) \\
\text { Reference }\end{array}$ & $\begin{array}{c}<0.001 \\
0.309\end{array}$ & $\begin{array}{c}1.25(1.06,1.48) \\
1.03(0.83,1.28) \\
\text { Reference }\end{array}$ & $\begin{array}{l}0.009 \\
0.757\end{array}$ \\
\hline $\begin{array}{l}\text { Region } \\
\text { Tigray } \\
\text { Afar } \\
\text { Amhara } \\
\text { Oromia } \\
\text { Somalia } \\
\text { Benishangul-Gumuz } \\
\text { SNNPR } \\
\text { Gambella } \\
\text { Harari } \\
\text { Dire Dawa } \\
\text { Addis Ababa } \\
\end{array}$ & $\begin{array}{c}2.89(2.27,3.67) \\
4.17(3.02,5.75) \\
1.83(1.43,2.35) \\
1.98(1.53,2.57) \\
4.45(3.38,5.87) \\
1.95(1.42,2.67) \\
1.59(1.22,2.07) \\
2.19(1.56,3.08) \\
1.80(1.33,2.45) \\
1.77(1.29,2.43) \\
\quad \text { Reference }\end{array}$ & $\begin{array}{c}<0.001 \\
<0.001 \\
<0.001 \\
<0.001 \\
<0.001 \\
<0.001 \\
0.001 \\
<0.001 \\
<0.001 \\
<0.001\end{array}$ & $\begin{array}{c}2.23(1.61,3.09) \\
2.98(2.04,4.36) \\
1.53(1.09,2.13) \\
1.53(1.07,2.19) \\
3.14(2.19,4.52) \\
1.58(1.06,2.35) \\
1.26(0.87,1.82) \\
1.89(1.29,2.76) \\
1.54(1.09,2.19) \\
1.45(1.03,2.05) \\
\quad \text { Reference }\end{array}$ & $\begin{array}{c}<0.001 \\
<0.001 \\
0.012 \\
0.021 \\
<0.001 \\
0.021 \\
0.211 \\
0.001 \\
0.014 \\
0.033\end{array}$ \\
\hline $\begin{array}{l}\text { Alcohol intake } \\
\text { Yes } \\
\text { No } \\
\end{array}$ & $\begin{array}{c}\text { Reference } \\
1.23(1.06,1.43)\end{array}$ & 0.006 & $\begin{array}{c}\text { Reference } \\
0.91(0.75,1.10)\end{array}$ & 0.318 \\
\hline
\end{tabular}

OR, odds ratio; CI, confidence interval, SNNPR, Southern Nations, Nationalities, and Peoples' Region; MDDS, minimum dietary diversity score. ${ }^{a}$ Widowed, separated, divorced, and living with a partner. ${ }^{*}$ The final regression model was adjusted for anemia, educational status, place of residence, wealth status, marital status, occupational status, adults' age, family size, alcohol consumption, and region.

were higher in adults who live lonely (95\% CI: 1.21, 1.71). Male adults who lived in Tigray region were 2.2 times $(\mathrm{AOR}=2.23,95 \% \mathrm{CI}: 1.61,3.09)$, Afar region were 2.9 times $(\mathrm{AOR}=2.98,95 \% \mathrm{CI}: 2.04,4.36)$, Amhara region were 1.5 times $(\mathrm{AOR}=1.53,95 \% \mathrm{CI} ; 1.09,2.13)$, Oromia region were 1.5 times $(\mathrm{AOR}=1.53,95 \% \mathrm{CI}: 1.07,2.19)$, Somali region were 3.1 times $(\mathrm{AOR}=3.14,95 \% \mathrm{CI}: 2.19,4.52)$, Gambella region were 1.9 times $(\mathrm{AOR}=1.89,95 \% \mathrm{CI}: 1.29,2.76)$, Harari region were 1.5 times $(\mathrm{AOR}=1.54,95 \% \mathrm{CI}: 1.09$, 2.19 ), and Diredawa town were 1.5 times $(\mathrm{AOR}=1.54,95 \%$ CI: $1.03,2.05)$ more likely to be chronic energy deficient compared to adults from Addis Ababa, respectively.

The likelihood of chronic energy deficiency was higher among adults residing in poor wealth index households than 
adults residing in rich wealth index households $(\mathrm{AOR}=1.25$; 95\% CI: 1.05, 1.48) (Table 3).

\section{Discussion}

Chronic energy deficiency among adults is one of the abandoned nutritional problems and is one of the contributors to morbidity and mortality together with decreased mental and cognitive development. It also reduces educational achievement and labor productivity [8-10, 29-31]. The prevalence of CED among adults in Ethiopia remains significantly high. The development of effective interventions aimed at reducing rates of undernutrition requires the identification of key risk factors of CED [2, 4, 20].

In a representative sample of Ethiopian adults aged 18-59 years, we found that the overall prevalence of CED was $28.7 \%$. Marital status, occupation, household wealth index, and region were significantly associated with chronic energy deficiency.

The prevalence of CED in this study was higher than from study performed in Uganda (22.3\%) [32], India (19.5\%) [33], Botswana (19.5\%) [14], and Tharu population, India (26.2\%) [34], Malaysia 8.5\% [35], and Colombia (2.8\%) [36]. However, it was lower than the study report from west India (40.1\%) [37]. These discrepancies might be due to sampling size, socioeconomic, and feeding habit differences between study setups.

The odds of CED among adult men who lived lonely were higher compared with married adult men. This might be explained by married adult men unlike adult lived lonely counterparts are more likely to be younger; they have a high risk of being underweight due to low intake of diet and dependency on the family. This finding is similar to many studies conducted elsewhere [14, 32]. Marriages mostly expose adults to be overweight/obese [38-40].

Compared to men who have work, the odds of CED were higher in adults who have no work. This might be explained by those men who have no work may not get enough money for food. The other possible justification could be because men with no work mostly consume less nutritious food which exposed them to CED. This finding is similar to many studies conducted elsewhere [41-44].

The likelihood of chronic energy deficiency was higher among adults residing in poor wealth index households than adults residing in rich wealth index households. Similar findings were reported from studies conducted elsewhere $[3,14,29,41,45]$. This could be due to those poorer households that are unable to purchase nutritionally adequate and diversified food for their family. This leads to inadequate food intake, exposure to infections, and lack of access to basic health services.

The odds of CED among Somali, Afar, Tigri, Gambella, Benishangul-Gumuz, Harari, Oromia, Amahara, and Dire Dawa adult men were 3.1, 2.9, 2.2, 1.9,1.6, 1.5, 1.5, 1.5, and 1.5 times higher than adults from Addis Ababa, respectively. The possible hypothesis could be feeding habits and the type of food production difference in the northeastern parts of Ethiopia.
The main strength of this study was that it used nationally representative data with a large sample size which could enhance the generalisability of the findings. However, this study had limitations that the EDHS survey is relied on respondents' self-report and might have the possibility of recall bias and social desirability bias as data were collected by a self-reported interview. Again, this study is a crosssectional study design, and it is difficult to establish causality between the outcome of interest and these important independent variables.

\section{Conclusion and Recommendation}

Chronic energy deficiency among male adults in Ethiopia was a high public health problem. Marital status, wealth index, occupation, and region were significant predictors of chronic energy deficiency. The Ministry of Health with other partners should strictly monitor and evaluate interventions that are being applied and should give focus to adult men to prevent malnutrition.

\section{Abbreviations}

AOR: Adjusted odd ratio

BMI: Body mass index

CED: Chronic energy deficiency

CSA: Central statistics agency

CI: Confidence interval

EDHS: Ethiopian Demographic Health Survey

NCDs: Noncommunicable diseases

NNP: National Nutrition Program

SDG: Sustainable development goal

WHO: World Health Organization.

\section{Data Availability}

The DHS data analyzed during the current study are available in the repository (https://dhsprogram.com/data).

\section{Ethical Approval}

The Institutional Review Board (IRB) of ICF and the National Ethics Review Committee at the Ministry of Science and Technology approved the protocol for the 2016 EDHS. Permission was obtained from the DHS program to download and use the data for this analysis.

\section{Conflicts of Interest}

The authors declare that they have no conflicts of interest.

\section{Authors' Contributions}

All authors conceived and designed the study. SD, YM, YW, and AA performed data analysis and interpretation. SD, SA, GD, and ML drafted the manuscript. ZH assisted in critically reviewing the manuscript. All authors read and approved the final manuscript. 


\section{Acknowledgments}

The authors would like to thank the DHS program for allowing using the data for this analysis.

\section{References}

[1] L. Abarca-Gómez, Z. A. Abdeen, Z. A. Hamid, N. M. AbuRmeileh, B. Acosta-Cazares, and C. Acuin, "Worldwide trends in body-mass index, underweight, overweight, and obesity from 1975 to 2016," The Lancet, vol. 390, no. 10113, pp. 2627-2642, 2017.

[2] J. Fanzo, C. Hawkes, E. Udomkesmalee, A. Afshin, L. Allemandi, and O. Assery, "Global Nutrition Report: shining a light to spur action on nutrition," 2018.

[3] S. Moore, J. N. Hall, S. Harper, and J. W. Lynch, "Global and national socioeconomic disparities in obesity, overweight, and underweight status," Journal of Obesity, vol. 2010, 2010.

[4] W. H. Organization, The Double Burden of Malnutrition: Policy Brief, World Health Organization, Geneva, Switzerland, 2016.

[5] W. P. James, A. Ferro-Luzzi, and J. C. Waterlow, "Definition of chronic energy deficiency in adults. report of a working party of the international dietary energy consultative group," European Journal of Clinical Nutrition, vol. 42, no. 12, pp. 969-981, 1988.

[6] W. H. Organization, World Health Organization Global Database on Body Mass Index, World Health Organization, Geneva, Switzerland, 2010.

[7] W. H. Organization, The International Classification of Adult Underweight, Overweight and Obesity According to BMI, World Health Organization, Geneva, Switzerland, 2004.

[8] G. B. Spurr, "Nutritional status and physical work capacity," American Journal of Physical Anthropology, vol. 26, no. S1, pp. 1-35, 1983.

[9] S. Broca and K. Stamoulis, "Micro-and macroevidence on the impact of undernourishment," Nutrition Intake and Economic Growth, 2003.

[10] A. Croppenstedt and C. Muller, "The impact of farmers' health and nutritional status on their productivity and efficiency: evidence from Ethiopia," Economic Development and Cultural Change, vol. 48, no. 3, pp. 475-502, 2000.

[11] C. Rotimi, I. Okosun, L. Johnson et al., "The distribution and mortality impact of chronic energy deficiency among adult Nigerian men and women," European Journal of Clinical Nutrition, vol. 53, no. 9, pp. 734-739, 1999.

[12] R. Chakraborty, K. Bose, and S. Bisai, "Relationship of family income and house type to body mass index and chronic energy deficiency among urban Bengalee male slum dwellers of Kolkata, India," Homo, vol. 60, no. 1, pp. 45-57, 2009.

[13] S. Bharati, M. Pal, B. N. Bhattacharya, and P. Bharati, "Prevalence and causes of chronic energy deficiency and obesity in women of India," Human Biology, vol. 79, no. 4, pp. 395-412, 2007.

[14] G. Letamo and K. Navaneetham, "Prevalence and determinants of adult under-nutrition in Botswana," PLoS One, vol. 9, no. 7, 2014.

[15] N. Risk, "Factor Collaboration (NCD-RisC). Trends in adult body-mass index in 200 countries from 1975 to 2014: a pooled analysis of 1698 population-based measurement studies with 19.2 million participants," Lancet, vol. 387, no. 10026, pp. 1377-1396, 2016.
[16] C. E. Demographic, Health Survey-2011. Central Statistical Agency Addis Ababa, Ethiopia ICF International, Calverton, MD, USA, 2012.

[17] Initiatives, "Global nutrition report 2018: shining a light to spur action on nutrition," 2018.

[18] C. Hayashi, J. Krasevec, R. Kumapley, V. Mehra, M. de Onis, and E. Borghi, "Levels and trends in child malnutrition," 2017.

[19] U. UNDP, Sustainable Development Goals, United Nations Development Programme, New York, NY, USA, 2015.

[20] W. H. Organization, Double-duty Actions for Nutrition: Policy Brief, World Health Organization, Geneva, Switzerland, 2017.

[21] Health FDRoEMo, HSTP Health Sector Transformation Plan 2015/16-2019/20 (2008-2012 EFY), Federal Democratic Republic of Ethiopia Ministry of Health, Addis Ababa, Ethiopia, 2015.

[22] E. FDRo, "National nutrition programme II: 2016-2020," 2016.

[23] E. GotFDR, "National nutrition programme June 2013-June 2015," 2013.

[24] FDRE, "Sekota declaration implementation plan 2016-2030," 2016.

[25] I. CSACE, Ethiopia Demographic and Health Survey 2016, Addis Ababa, Ethiopia, and Rockville, CSA and ICF, Rockville, MD, USA, 2016.

[26] W. H. Organization, WHO STEPS Surveillance Manual: The WHO STEPwise Approach to Chronic Disease Risk Factor Surveillance, World Health Organization, Geneva, Switzerland, 2005.

[27] F. FAOFood and Agriculture Organization of the United Nations, Rome, Italy, 1996.

[28] S. Rutstein, The DHS Wealth Index: Approaches for Rural and Urban Areas. Demographic and Health Research, Macro International, MEASURE DHS DHS Working Papers, Calverton, MD, USA, 2008.

[29] A. K. Subasinghe, K. Z. Walker, R. G. Evans, V. Srikanth, S. Arabshahi, and K. Kartik, "Association between farming and chronic energy deficiency in rural South India," PLoS One, vol. 9, no. 1, Article ID e87423, 2014.

[30] D. Thomas and J. Strauss, "Health and wages: evidence on men and women in urban Brazil," Journal of Econometrics, vol. 77, no. 1, pp. 159-185, 1997.

[31] S. S. Strickland, "Functional consequences of adult malnutrition in developing countries: a review," Journal of Physiological Anthropology and Applied Human Science, vol. 21, no. 1, pp. 1-9, 2002.

[32] S. Schramm, F. O. Kaducu, S. A. Smedemark, E. Ovuga, and M. Sodemann, "Gender and age disparities in adult undernutrition in northern Uganda: high-risk groups not targeted by food aid programmes," Tropical Medicine \& International Health, vol. 21, no. 6, pp. 807-817, 2016.

[33] M. Dutta, Y. Selvamani, P. Singh, and L. Prashad, "The double burden of malnutrition among adults in India: evidence from national family health survey 4 (2015-16)," Epidemiology and Health, vol. 6, Article ID e2019050, 2019.

[34] K. Mukherjee, "Body mass index and chronic energy deficiency among adults of Tharu population, Uttarakhand, India," Facilities, vol. 3, p. 4, 2015.

[35] C. Wong, M. Zalilah, E. Chua, S. Norhasmah, Y. Chin, and A. S. Nur'Asyura, "Double-burden of malnutrition among the indigenous peoples (Orang Asli) of Peninsular Malaysia," BMC Public Health, vol. 15, no. 1, p. 680, 2015.

[36] O. L. Sarmiento, D. C. Parra, S. A. González, I. GonzálezCasanova, A. Y. Forero, and J. Garcia, "The dual burden of 
malnutrition in Colombia," The American Journal of Clinical Nutrition, vol. 100, no. 6, pp. 1628S-1635S, 2014.

[37] A. Bhattacharya, B. Pal, S. Mukherjee, and S. K. Roy, "Assessment of nutritional status using anthropometric variables by multivariate analysis," BMC Public Health, vol. 19, no. 1, p. $1045,2019$.

[38] C. A. Duante, J. L. Q. Canag, C. F. Patalen, R. E. G. Austria, and C. C. S. Acuin, "Factors associated with overweight and obesity among adults 20.0 Years and over: results from the 2013 national nutrition survey, Philippines," Philippines Journal of Science, vol. 148, no. 1, pp. 7-20, 2019.

[39] T. Tzotzas, G. Vlahavas, S. K. Papadopoulou, E. Kapantais, D. Kaklamanou, and M. Hassapidou, "Marital status and educational level associated to obesity in Greek adults: data from the National Epidemiological Survey," BMC Public Health, vol. 10, no. 1, p. 732, 2010.

[40] D. Umberson, H. Liu, and D. Powers, "Marital status, marital transitions, and body weight," Journal of Health and Social Behavior, vol. 50, no. 3, pp. 327-343, 2009.

[41] M. Dutta, Y. Selvamani, P. Singh, and L. Prashad, "The double burden of malnutrition among adults in India: evidence from the National Family Health Survey-4 (2015-16)," Epidemiology and Health, vol. 41, 2019.

[42] A. Hughes and M. Kumari, "Unemployment, underweight, and obesity: findings from understanding society (UKHLS)," Preventive Medicine, vol. 97, pp. 19-25, 2017.

[43] D. Etana and D. Tolossa, "Unemployment and food insecurity in urban Ethiopia," African Development Review, vol. 29, no. 1, pp. 56-68, 2017.

[44] H. Assefa, T. Belachew, and L. Negash, "Socioeconomic factors associated with underweight and stunting among adolescents of Jimma Zone, south west Ethiopia: a crosssectional study," International Scholarly Research Notices, vol. 2013, 2013.

[45] K. Bose, S. Bisai, P. Das, S. Dikshit, and S. Pradhan, "Interrelationships of income, chronic energy deficiency, morbidity and hospitalization among adult male slum dwellers of Midnapore, West Bengal, India," Journal of Biosocial Science, vol. 39, no. 5, pp. 779-786, 2007. 